\title{
Early PCD events in male gametophyte development of isopropyl-N-phenyl carbamate resistant Nicotiana sylvestris mutant
} lines

\author{
Alla I Yemets*1, Oksana A Stelmakh ${ }^{1}$, Elena A Kravets ${ }^{2}$ and \\ Yaroslav B Blume ${ }^{1}$
}

\begin{abstract}
Address: ${ }^{1}$ Department of Genomics and Biotechnology, Institute of Cell Biology and Genetic Engineering, National Academy of Sciences of Ukraine, acad. Zabolotnogo str., 148, Kiev, 03143, Ukraine and 2Department of Plant Biophysics and Radiobiology, Institute of Cell Biology and Genetic Engineering, National Academy of Sciences of Ukraine, acad. Zabolotnogo str., 148, Kiev, 03143, Ukraine
\end{abstract}

Email: Alla I Yemets* - alyemets@univ.kiev.ua

* Corresponding author

from Cell Biology of Nitric Oxide and Cell Death in Plants

Yalta, Ukraine, 8-II September 2004

Published: 3I May 2005

BMC Plant Biology 2005, 5(Suppl I):S38 doi:I0.I I86/I47I-2229-5-SI-S38

\section{Background}

Microtubules provide structural support for cells and play a key role in mitosis and meiosis. They also play a key role in plant cell differentiation, new tissue and organ formation through a coordinated program of symmetric or asymmetric cell division. It is well known that microtubule-damaging agents suppress microtubule dynamics, leading to disruption of the mitotic spindle in dividing cells, cell cycle arrest at $\mathrm{M}$-phase, and the late apoptosis [1]. A better understanding of the processes coupling microtubule damage to the onset of apoptosis will help to find out in process of higher plants development. Recently, the mutant Nicotiana lines with high resistance to antimitotic herbicide isopropyl- $N$-phenyl carbamate (IPC) were produced [2,3]. Detailed analysis of IPC-resistant Nicotiana sylvestris plants revealed some abnormalities in microsporogenesis leading to partial pollen sterility. Here we report that these mutant $N$. sylvestris lines conferring resistance to IPC demonstrate clearly programmed cell death (PCD) events in male gamethophyte formation and development.

\section{Materials and methods}

IPC-resistant and control (sensitive) N. sylvestris plants grown in in vitro conditions and greenhouse were used in this study. Sterile plants of both lines were placed from in vitro conditions to soil for adaptation, and then they were grown in greenhouse.
For cytological analysis the roots of control and mutant $N$. sylvestris lines were treated with $30 \mathrm{mkM}$ IPC for $24 \mathrm{~h}$, fixed in an ethanol/acetic acid mixture (3:1) for $12 \mathrm{~h}$, stained with acetoorcein ( $1 \%$ solution in $45 \%$ acetic acid) for $24 \mathrm{~h}$ and examined. Bud seeds and anthers were fixed accordingly protocols [4]. After washing the samples were kept in $70 \%$ ethanol. The samples were underwent an alkali and enzyme treatment before staining with acetoorcein.

\section{Results}

The resistance to IPC in mutant $N$. sylvestris lines were confirmed by us by series of tests and morphocytochemical analyses. For instance, the morphocytochemical analysis of control and mutant lines revealed 6-8 times more resistance to IPC of mutant line as compared with control one. It was found also that the increasing doses of IPC lead to dramatic changes in nucleus and microtubule network in sensitive plants. In control plants tripolar anaphases and telophases were found after treatment with 30 MkM IPC. IPC-treatment resulted also in high number of metaphase+anaphase (from $32.48 \%$ in control cells without treatment to $80.07 \%$ after treatment) and accumulation of multinuclear cells and lobbed nuclei in treated control cells (see Figure 1d-f).

Threshold level of IPC induced an apoptotic process, characterised by cell cycle arrest, hypercondensation of chromatin, an appearance of lobbed nuclei; abnormal, multipolar mitotic spindles, post-mitotic micronuclei 

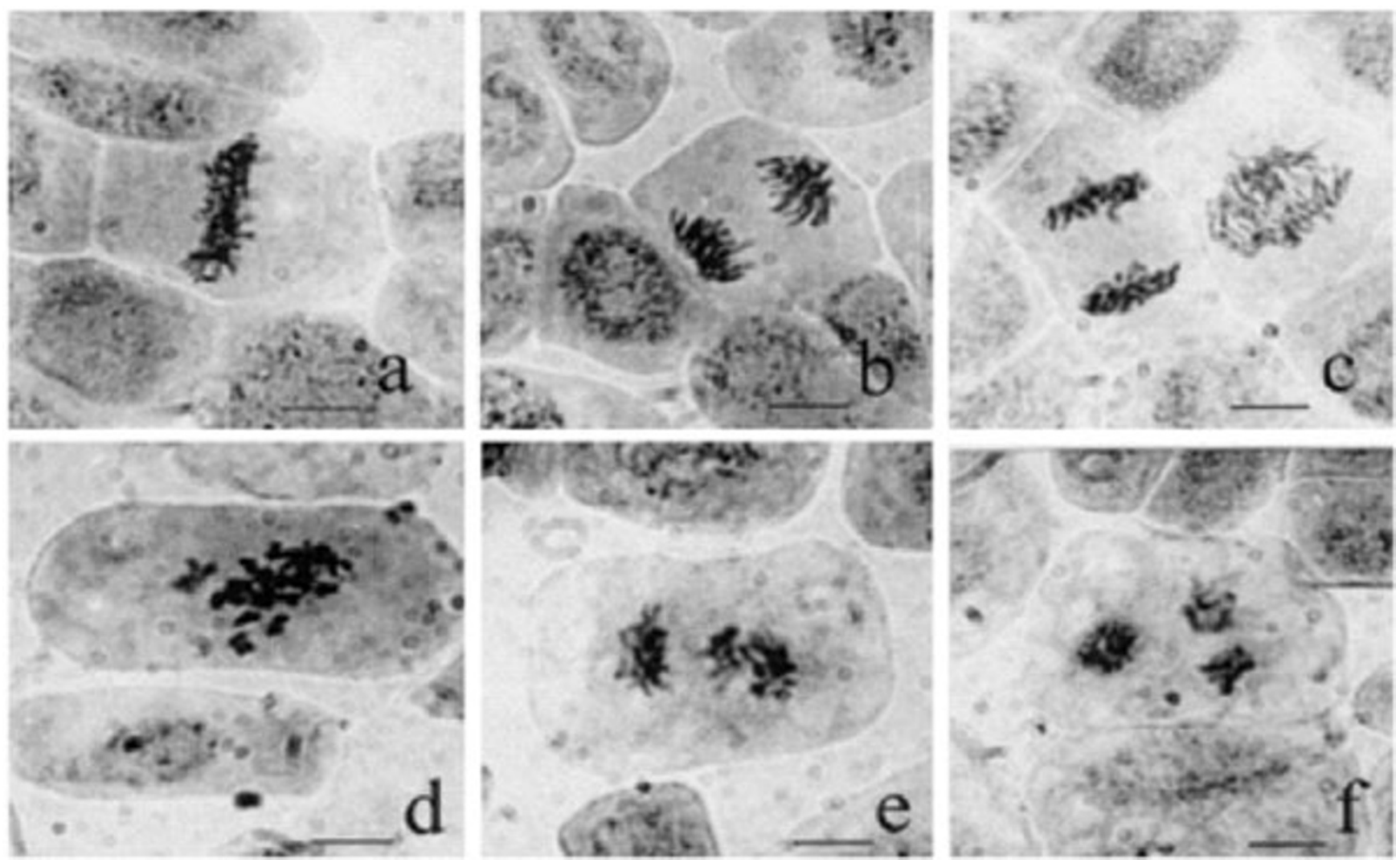

Figure I

Mitotic figures in resistant (a-c) and sensitive (d-f) N. sylvestris lines after $30 \mathrm{MkM}$ treatment. Bar $=1000 \mathrm{~mm}$.

formation due to nuclei fragmentation in the root cells of sensitive lines. However, root meristematic cells from resistant plants revealed no disturbances in cell cycle progression after treatment with 30 MkM IPC (see Figure 1ac).

Further investigations shown that control and mutant $N$. sylvestris plants possessed some morphological differences (see Figure 2). Mutant plants characterised in certain depression resulted in reduction of sizes of vegetative and generative organs, and of plant bodies on the whole. There were slight differences in the appearance of flowers (see Figure 3a) and more visible differences in the length of stamens and pistils between control and mutant lines (see Figures $3 b$ and $3 c$ ).

More detailed analysis of reproductive organs development of IPC-resistant mutants revealed that microspores in anthers are subjected to degenerative process, leading to pollen sterility. It was found also the chromatin agglutination in nuclei of most part of microsporocytes.
During study the microsporogenesis in IPC-mutant plants it was revealed the formation of microspores of different sizes (gigantic, medium and dwarfic: $15.05 \pm 0.06 \mathrm{mkm}$, $7.50 \pm 0.23 \mathrm{mkm}$ and $5.15 \pm 0.13 \mathrm{mkm}$ in size, respectively) and in different numbers (dyads, triads and polyads). In the same time normal tetrads produced in control N. sylvestris plants (data not shown). Variation in sizes and numbers indicates on disturbances in chromosome separation in I and II meiotic divisions, loss the second division in one (in the case of triads) and in both dyads, the formation of multipolar spindles (in the case of polyads) in mutants.

It was established that pollen grains of control plants possessed the high level of fertility $(97.12 \pm 0.33 \%)$; they were homogenous and synchronous in development. Whereas, genetically non-balanced microscopes of mutant lines after tetrad dissipation were unable to further development. They did not synthesise the fats and new cytoplasm and underwent typical cell death. Only $14.73 \pm 1.09 \%$ formed microspores got down later to division with vegetative and generative cells formation. 




Figure 2

The view of flowering parts of N. sylvestris control (a) and 30 MkM IPC-resistant (b) lines.

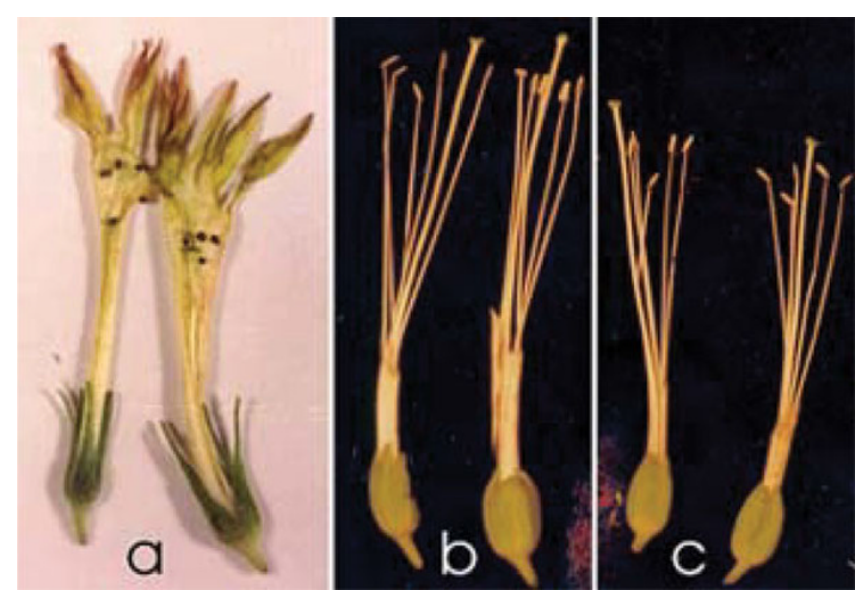

Figure 3

(a) An appearance of flowers of $N$. sylvestris control (left) and mutant (right) lines; Flower generative organs of $N$. sylvestris control (b) and mutant (c) lines.

As a result, the common number of pollen was reduced in anthers of mutant plants. About $2.88 \pm 0.33 \%$ of bicellular pollen grains were hydrated and stopped in development. Consequently, the mature pollen of mutant plants was morphologically and functionally non-homogenous. Its fertility in different flowers was from 7.63 to $27.93 \%$. Sterile pollen grains were small, weakly stained or nonstained after incubation with dye (see Figure 5b). They also had reduced contents of cytoplasm as compared with control plants.
The results of female gametophyte study in mutant and control N. sylvestris plants demonstrated that ovary development after pollination was lower in 1.5-2 times in mutant plants as compare with control ones (see Figure $6)$. The delay in growth and development was connected with the high number of non-fertilized bud seeds (see Figure 7) in mutant plants. We found strong correlation between fertility level of pollen and a number of fertilized bud seeds in these plants.

Analysis of fertilized bud seeds of N. sylvestris mutants shown that bud seeds were different in the sizes that indicates on their non-homogeneous and asynchronous development as compare with control plants. It was found that a speed of embryos development in mutant plants was lower than that in control lines, and sometimes an embryo development stopped on early globular stage. Therefore, the seed production in mutant plants was very low due to both high pollen sterility and decreased viability of bud seeds development.

\section{Conclusion}

Programmed cell death has been observed to occur during many stages of plant reproduction [5] as PCD is essential for development and survival of plants. But there are still a lot of open questions about genes and their products which might function as signals to evoke a cell suicide program, in particular, during male gametophyte development. Comprehensive reviews about the mutants known to affect meiosis [6] and about the genes controlled of male gametophyte development [7] help to understand and clarify certain moments in this issue, but not completely. We suggest also that cytoskeleton proteins, in particular, different isoforms of alpha-, beta- and gamma-tubulins as well as other microtubule organising centre (MTOC) proteins may play a crucial role in many processes of microsporogenesis.

Summarising obtained results we can consider that all established abnormalities in male reproductive organ development leading to PCD in pollen production can be arise from a mutation of the microtubule protein(s) in IPC-resistant $N$. sylvestris lines. We hypothesize also that the mutant protein(s) may represent(s) a key biological trigger in the expression of physiological death at the cellular level in these plants.

The analysis of IPC-resistant N. sylvestris plants is continuing to determine the role of certain mutant cytoskeletal gene(s) which is/are express(es) in male gametophyte and lead to PCD during pollen production for better understanding the male reproductive organ development. 




\section{Figure 4}

Disturbances on the stage of late tetrad in N. sylvestris mutant plant anthers: I - dyad, 2 - triad, 3 - atypical tetrad, 4 - pentad, 5 - hexad, 6 - polyad. Bar $=0.005 \mathrm{~mm}$.

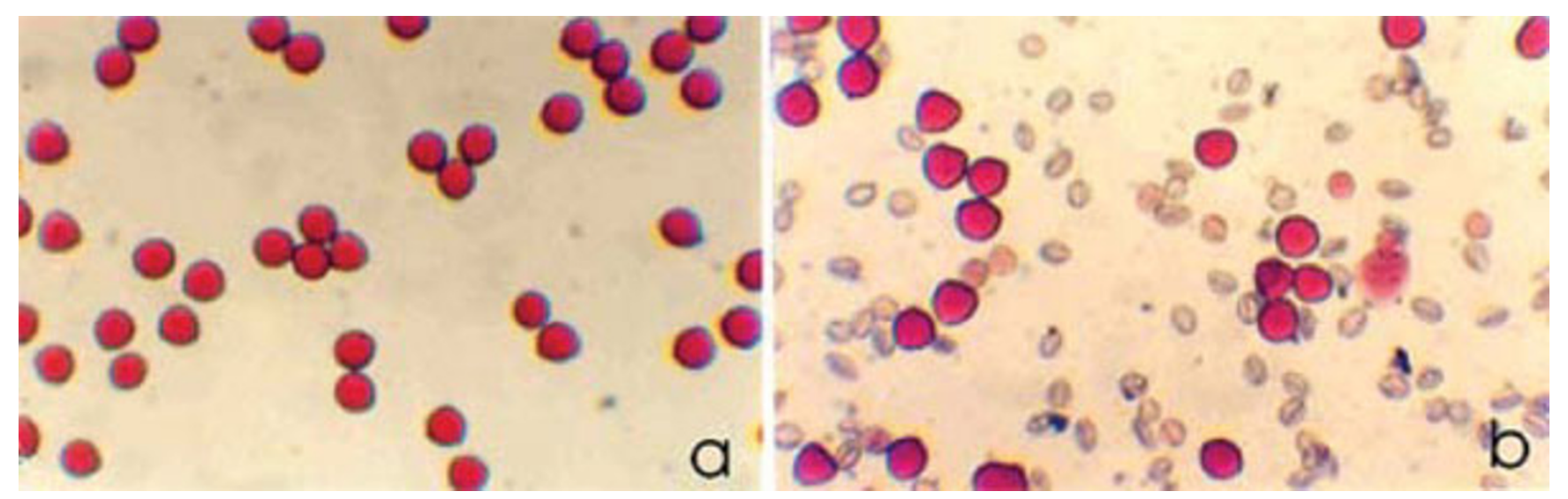

Figure 5

(a) Mature pollen grains from N. sylvestris control (a) and mutant (b) lines. Fertile pollen grains are stained, non-fertile are not stained by acetoorcein. 


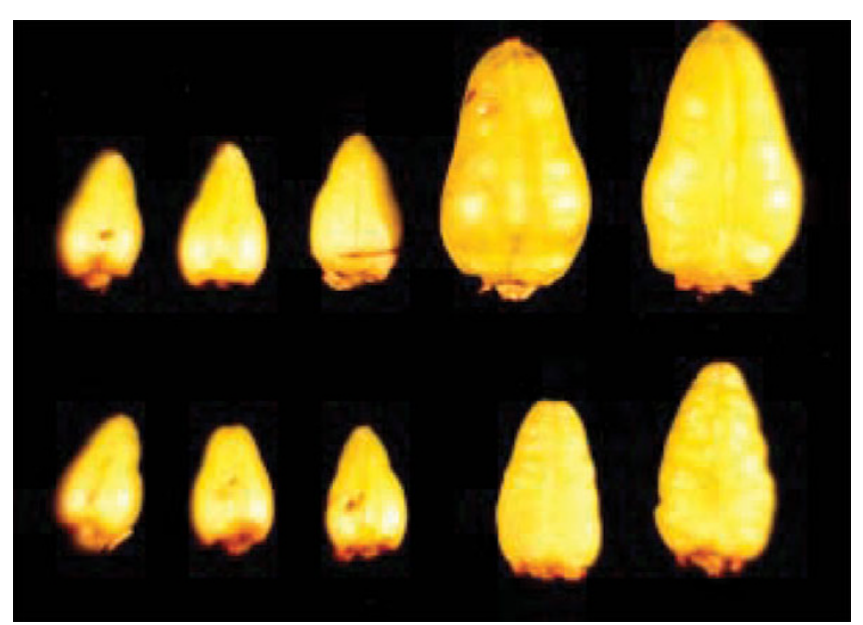

Figure 6

Ovaries of $N$. sylvestris control (at the top of the picture) and mutant (below on the picture) lines straight away after pollination, and after one, two, three and four weeks of development.

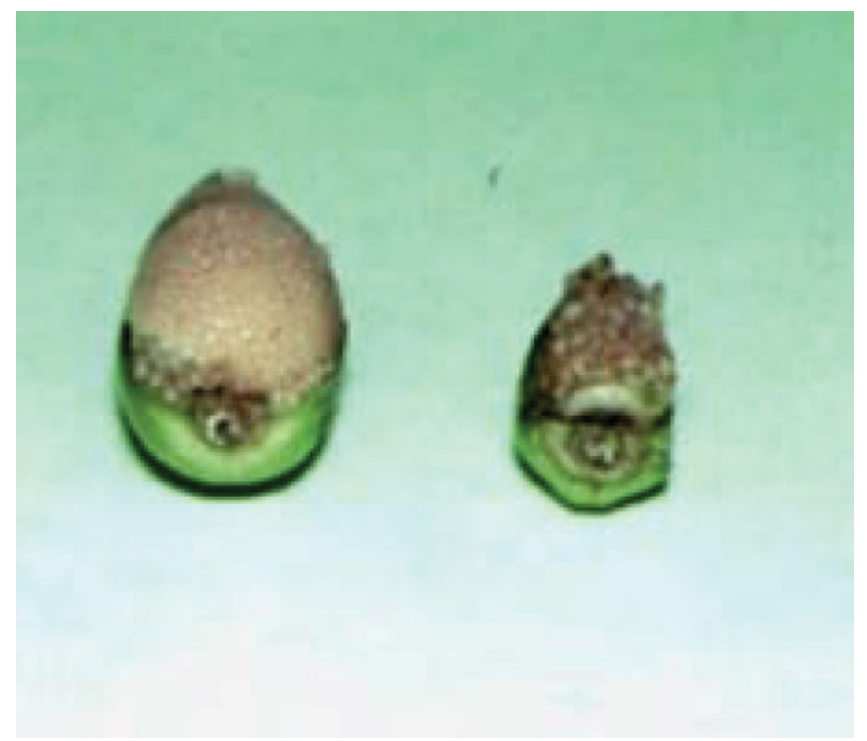

\section{Figure 7}

Three-weeks old ovaries in section of N. sylvestris control (left) and mutant (right) plants after pollination.

\section{References}

I. Mollinedo F, Gajate C: Microtubules, microtubule-interfering agents and apoptosis. Apoptosis 2003, 8:413-450.

2. Yemets Al, Mileyko AA, Blume YaB: Obtaining the mutants of Nicotiana plumbaginifolia $\mathrm{L}$. resistant to herbicide isopropylN-phenylcarbamate. Proc Natl Acad Sci Ukraine 2000, 10:182-187.
3. Yemets A, Stelmakh $O$, Kundelchuk $O$, Blume YaB: Obtaining and analysis of isopropyl- $\mathrm{N}$-phenyl carbamate resistant lines of Nicotiana species. Cell Biol lnt 2003, 27:307-3I0.

4. Pausheva ZP: Manual on plant cytology. Moscow, Kolos Press; 1974:189-219.

5. Greenberg JT: Programmed cell death: a way of life for plants. Proc Natl Acad Sci USA 1996, 93: I 2094- 2097.

6. Caryl AP, Jones GH, Franklin FC: Dissecting plant meiosis using Arabidopsis thaliana mutants. J Exp Bot 2003, 54:25-38.

7. McCormick S: Control of male gamethophyte development. Plant Cell 2004, 16:SI42-SI53.
Publish with Bio Med Central and every scientist can read your work free of charge

"BioMed Central will be the most significant development for disseminating the results of biomedical research in our lifetime. "

Sir Paul Nurse, Cancer Research UK

Your research papers will be:

- available free of charge to the entire biomedical community

- peer reviewed and published immediately upon acceptance

- cited in PubMed and archived on PubMed Central

- yours - you keep the copyright
BioMedcentral 